\title{
Laryngopharyngeal Reflux: An Update
}

\author{
Chin-Lung Kuo, MD, PhD $1,2,3 *$ \\ 1 Department of Otolaryngology, Taoyuan Armed Forces General Hospital, Taoyuan, Taiwan \\ 2 Institute of Brain Science, National Yang-Ming University School of Medicine, Taipei, Taiwan \\ ${ }^{3}$ Department of Otolaryngology, Tri-Service General Hospital, National Defense Medical Center, Taipei, Taiwan
}

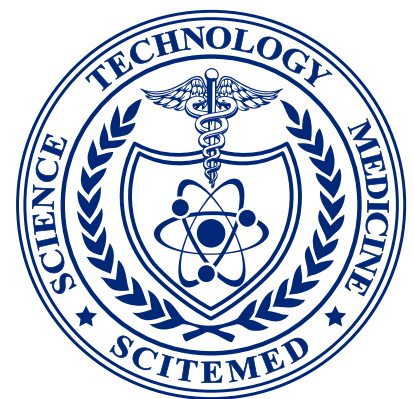

\begin{abstract}
The etiopathogenesis of laryngopharyngeal reflux (LPR) involves direct caustic irritation of gastroduodenal materials and indirect laryngeal reflexes invoked by refluxate. The most common symptoms include throat clearing, persistent cough, globus pharyngeus, and hoarseness. There is only a weak correlation between LPR symptoms and endoscopic findings. It is not recommended to make a diagnosis of LPR solely based on laryngoscopic results. LPR treatment generally requires an aggressive approach, including high doses of proton pump inhibitors over long periods (twice daily for 3-4 months). Additional management options include lifestyle changes, dietary modifications, weight reduction, and exercise. Laparoscopic anti-reflux surgery has been shown to reduce LPR-associated symptoms; however, surgery should only be considered for patients who have a high quantity of refluxate and esophageal complications. In this review article, we suggest a multidisciplinary approach to LPR diagnosis, involving otolaryngologists, gastroenterologists, and pulmonologists. Based on the latest findings, we propose an algorithm to facilitate the assessment and management of LPR.
\end{abstract}

\section{Introduction}

Laryngopharyngeal reflux (LPR), also referred to as extra-esophageal reflux, supra-esophageal reflux, or silent reflux, refers to a condition in which gastroduodenal content rises up the esophagus and affects the throat, specifically the laryngopharynx [1-6]. In some cases, gastric content may even reach the nasal cavities and/or ears via the Eustachian tubes, which can exacerbate rhinitis, sinusitis, or otitis media [7-9].

Otolaryngologists and gastroenterologists differ in their definitions and management of LPR [4,10-12]. Otolaryngologists treat LPR as a relatively new clinical entity, whereas gastroenterologists treat LPR as a rare extra-esophageal manifestation of gastroesophageal reflux disease (GERD) $[10,13]$. Gastroenterologists have questioned whether reflux contributes to LPR-related symptoms in patients with no GERD-associated manifestations [11]. Otolaryngologists have pointed out that LPR is a multifactorial syndrome that also involves gaseous and/or nonacid refluxate $[14,15]$.

In this article, we examine the clinical manifestations, diagnosis, and current recommended treatments of LPR. Based on the latest findings in LPR research, we propose an algorithm aimed at facilitating the assessment and management of LPR.

\section{Differences Between LPR and GERD}

Despite similarities between LPR and GERD, these are two distinct disease entities. The retrograde flow of gastroduodenal contents into the esophagus and/or adjacent structures can lead to complications or troublesome reflux-associated symptoms, such as throat clearing, heartburn, and globus pharyngeus. Reflux diseases can be categorized as LPR, erosive esophagitis, and nonerosive reflux disease (NERD). Cases of erosive esophagitis and NERD are categorized as GERD [16].

In GERD, the reflux of gastric contents is limited to the esophagus. In LPR, the reflux of gastric content affects the larynx and phar$y n x$ [12]. Despite occasional cross-diagnoses of GERD and LPR, there are essential differences (Table 1). GERD is accompanied by acidity and heartburn (retrosternal burning), which is rarely encountered in LPR patients [12]. In GERD, reflux and acidity typically occur during the night (nocturnal refluxers). In LPR, reflux typically occurs during the day (daytime refluxers) [12]. LPR symptoms occur when patients are in an upright position during periods of physical exertion (e.g., bending over, Valsalva, and exercise) $[11,12,17]$, whereas GERD reflux occurs while patients are lying down.
Sphincters that prevent the stomach reflux from moving backwards play an important role in both diseases. Many GERD patients experience dysmotility and prolonged acidity when the lower esophageal sphincter malfunctions, thereby allowing stomach acid to move up the esophagus, causing heartburn $[12,18]$. LPR is associated with a failure of the upper sphincters, which allows the acid to move up to the throat and even into the nose or middle ears [7-9,12]. LPR patients commonly present tissue damage of the laryngopharyngeal epithelium $[12,19]$.

The typical manifestations of GERD include heartburn, regurgitation, and chest pain. The typical manifestations of LPR include asthma, chronic cough, hoarseness, globus sensation, and laryngitis in adult patients. LPR patients do not usually report symptoms of heartburn, which is common in GERD patients. It is often difficult to differentiate between LPR and GERD due to overlap in the symptoms. LPR rarely occurs in isolation; i.e., without concomitant symptoms typical of GERD $[20,21]$. Researchers have identified a correlation between the presence of LPR and the severity of GERD; however, similarities between the two may lead to underestimates of the incidence of LPR [22]. The diagnostic sine qua non of GERD, namely endoscopic esophageal mucosal breaks (erosion or ulceration), has been reported in only $25 \%$ of patients with LPR $[12,18]$.

\begin{tabular}{l|l|}
\multicolumn{1}{|c|}{ Table 1. Differences Between GERD and LPR } \\
$\begin{array}{l}\text { Accompanied by esophagitis and/ } \\
\text { or heartburn }\end{array}$ & $\begin{array}{l}\text { Esophagitis or heartburn is rarely } \\
\text { present }\end{array}$ \\
\hline $\begin{array}{l}\text { Reflux is nocturnal or in supine } \\
\text { position }\end{array}$ & $\begin{array}{l}\text { Reflux during daytime or in } \\
\text { upright position }\end{array}$ \\
\hline $\begin{array}{l}\text { Abnormal esophageal motility } \\
\text { and prolonged esophageal acid } \\
\text { exposure }\end{array}$ & Intermittent episodes of reflux \\
\hline $\begin{array}{l}\text { Dysfunction of the lower } \\
\text { esophageal sphincter }\end{array}$ & $\begin{array}{l}\text { Dysfunction of the upper } \\
\text { esophageal sphincter }\end{array}$ \\
\hline $\begin{array}{l}\text { Throat related symptoms are } \\
\text { sometimes present }\end{array}$ & $\begin{array}{l}\text { Leads to throat related } \\
\text { symptoms and damage to the } \\
\text { laryngopharyngeal epithelium }\end{array}$ \\
\hline
\end{tabular}

GERD, gastroesophageal reflux disease; LPR, laryngopharyngeal reflux. 
Table 2. Reflux Symptom Index (RSI)

\begin{tabular}{|c|c|c|c|c|c|c|c|}
\hline \multirow{2}{*}{$\begin{array}{c}\text { Item } \\
1\end{array}$} & \multirow{2}{*}{$\begin{array}{c}\text { Symptom }^{1} \\
\text { Hoarseness or a problem with your voice }\end{array}$} & \multicolumn{6}{|c|}{ Score $^{2}$} \\
\hline & & 0 & 1 & 2 & 3 & 4 & 5 \\
\hline 2 & Clearing your throat & 0 & 1 & 2 & 3 & 4 & 5 \\
\hline 3 & Excess throat mucous or postnasal drip & 0 & 1 & 2 & 3 & 4 & 5 \\
\hline 4 & Difficulty swallowing food, liquids or pills & 0 & 1 & 2 & 3 & 4 & 5 \\
\hline 5 & Coughing after you ate or after lying down & 0 & 1 & 2 & 3 & 4 & 5 \\
\hline 6 & Breathing difficulties or choking episodes & 0 & 1 & 2 & 3 & 4 & 5 \\
\hline 7 & Troublesome or annoying cough & 0 & 1 & 2 & 3 & 4 & 5 \\
\hline 8 & Sensations or something sticking in your throat & 0 & 1 & 2 & 3 & 4 & 5 \\
\hline 9 & Heart burn, chest pain, indigestion, or stomach & 0 & 1 & 2 & 3 & 4 & 5 \\
\hline
\end{tabular}

${ }^{1}$ Patients are asked to determine how the associated problems affect them within the last month.

${ }^{2} 0-5$ rating scale with $0=$ no problem and $5=$ severe.

Laryngopharyngeal reflux is considered if RSI > 13 .

\begin{tabular}{|c|c|c|}
\hline Item & Symptom & Score \\
\hline 1 & Subglottic edema (pseudosulcus) & $0=$ absent, $2=$ present \\
\hline 2 & Ventricular obliteration & $0=$ none, $2=$ partial, $4=$ complete \\
\hline 3 & Erythema/hyperemia & $0=$ none, 2 = arytenoids only, 4 = diffuse \\
\hline 4 & Vocal fold edema & $0=$ none, $1=$ mild, $2=$ moderate, $3=$ severe, $4=$ polypoid \\
\hline 5 & Diffuse laryngeal edema & $0=$ none, $1=$ mild, $2=$ moderate, $3=$ severe, $4=$ obstructing \\
\hline 6 & Posterior commissure hypertrophy & $0=$ none, $1=$ mild, $2=$ moderate, $3=$ severe, $4=$ obstructing \\
\hline 7 & Granuloma/granulation & 0 = absent, 2 = present \\
\hline 8 & Thick endolaryngeal mucus & $0=$ absent, $2=$ present \\
\hline
\end{tabular}

Laryngopharyngeal reflux is considered if RFS $>7$.

\section{Etiopathogenesis of LPR}

The etiopathogenesis of LPR involves direct as well as indirect mechanisms. The reflux components, which contain hydrochloric acid, pepsin, and bile acids, can irritate the laryngeal mucosa [2,23-26]. Reflux episodes in the esophagus can occur up to fifty times without harmful effects, whereas reflux in the larynx cause mucosal damage after just three episodes $[13,23]$. Direct refluxate irritation can cause local mucosal inflammation and subsequent laryngospasm. Up-regulated sensitivity in laryngeal sensory endings can lead to coughing and choking [27].

The indirect mechanism involves laryngeal reflexes evoked by refluxate that does not reach laryngeal tissue. Reflex evokes a vagally mediated change, resulting in clinical symptoms, including chronic cough and asthma-like symptoms though bronchoconstriction. A decrease in the resting tone of the upper and lower esophageal sphincters and increases in intraabdominal pressure are also associated with the refluxate bolus and subsequent occurrence of LPR [11,28-35].

Direct and indirect irritation can have consequences for the vocal cords, such as vocal edema, pseudosulcus of vocal cords, contact ulcers, and contact granulomas associated with hoarseness, globus pharyngeus, and sore throat $[14,18]$. Pseudosulcus of vocal cords associated with infraglottic edema has been identified in $90 \%$ of patients with LPR [14,36].

Eating habits, tight clothing, stress, and excess weight have also been shown to contribute to LPR. This condition is more common among people who habitually consume acidic, oily, or spicy preparations. The consumption of alcohol is also a contributory factor. Tight clothing sometimes causes acid to swell up into the food pipe resulting in LPR. Stress can induce an increase in acidity levels and has been shown to cause LPR. Overweight people are more prone to this condition [2].

\section{Clinical Manifestations}

The most common symptoms of LPR include throat clearing, persistent cough, globus pharyngeus, and hoarseness [3,11,14,18,37]. Globus pharyngeus is a non-painful sensation of a lump or foreign body in the throat [38]. Heartburn is the most common symptom of GERD, occurring in more than $75 \%$ of cases [39]; however, fewer than $40 \%$ of patients with LPR report heartburn [11,12]. Reichel and Issing reported that Barrett's metaplasia or grade $B$ esophagitis was diagnosed only in patients in which heartburn was the main presenting symptom [40]. This suggests that upper gastrointestinal endoscopy (UGE) may be indicated in LPR patients reporting heartburn as their main complaint in order to exclude structural injuries or neoplasms.

Many of the LPR symptoms are nonspecifically associated with nasal conditions, such as allergies and postnasal drip [41,42]. LPR has been shown to have a negative effect on nasal resistance and nasal congestion [43]. Treatment associated with LPR may improve subjective and objective nasal problems [43]. Studies also revealed an association between LPR and halitosis, taste, or smelling disorders $[44,45]$. Researchers have recently reported that acid reflux may be associated with middle and inner ear problems, such as otitis media, tinnitus, and peripheral vertigo [46-48]. The mechanism underlying these inner ear disorders may be associated with reflux material (specifically hydrochloric acid and pepsin) leaking into the middle ear via the Eustachian tubes and affecting osseous structures.

\section{Diagnostic Tools}

\section{Reflux Symptom Index (Table 2)}

The reflux symptom index (RSI) can assist in diagnosing LPR $[49,50]$. The RSI is derived using a simple nine-item questionnaire in which patients rate the severity of their LPR symptoms on a Likert scale, with 0 repre- 


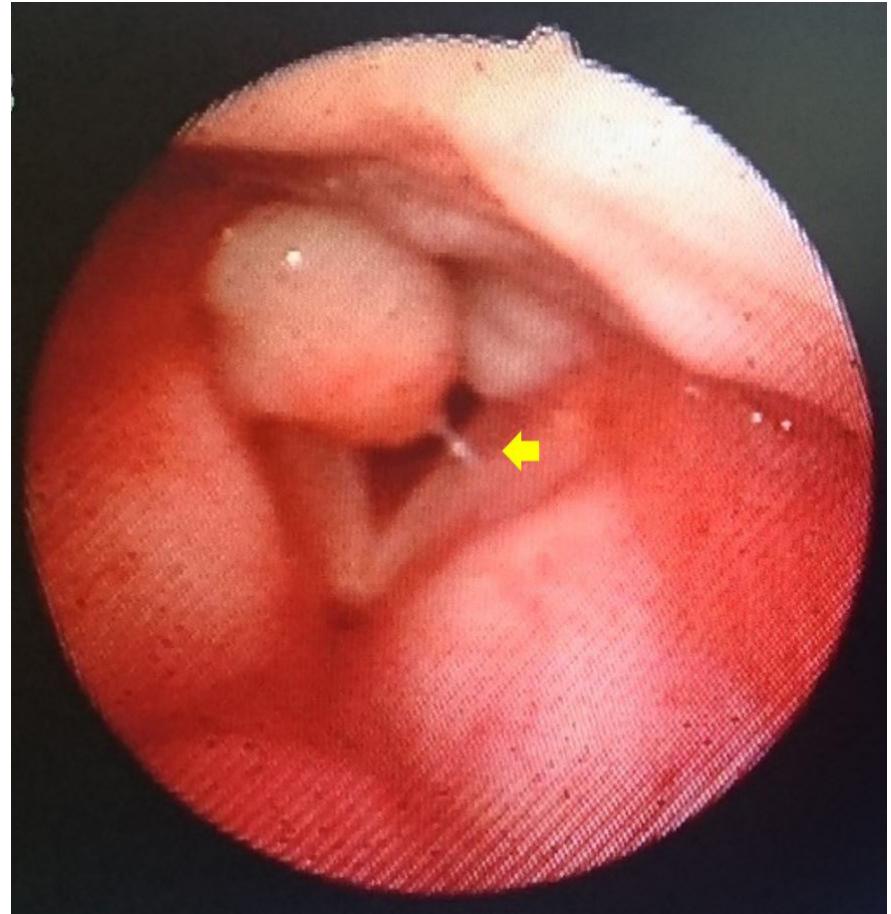

Figure 1. Laryngoscopic image showing a larynx with large bilateral granulomas on the surface of arytenoids. A prominent pseudosulcus is identified by the arrow.

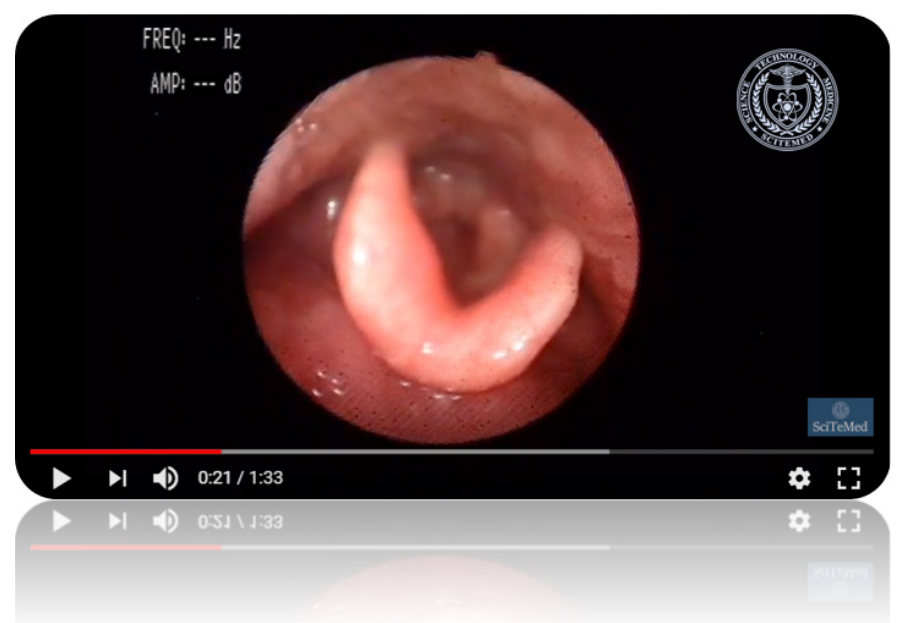

Video 1. Laryngoscopic examination for signs of laryngeal irritation associated with reflux. Large bilateral granulomas are identified on the surface of arytenoids. Video link: https://doi.org/10.24983/scitemed. aohns.2019.00094

senting no problem and 5 representing extreme problems. The maximum score is 45 , and a score of more than 13 is diagnosed as abnormal acid reflux [50].

\section{Laryngoscopic Examinations}

Laryngoscopic examinations for signs of laryngeal irritation associated with reflux are performed using flexible transnasal or rigid transoral laryngoscopes. One prospective study reported that signs of laryngeal irritation are more often detected with flexible than with rigid laryngoscopes [51]. The key features of laryngeal irritation include ventricular obliteration, vocal fold edema, subglottic edema (pseudosulcus) as well as thickening, redness, and edema mainly localized in the posterior larynx involving posterior pharyngeal wall, arytenoids, and interarytenoid area $[6,36,52]$.
Nonetheless, there is only a weak correlation between LPR symptoms and endoscopic findings. In a prospective study that included 52 nonsmokers, laryngoscopy revealed signs of laryngeal irritation in over $80 \%$ of cases [51]. Furthermore, the laryngoscopic diagnosis of LPR can be highly subjective, depending largely on the expertise and experience of the clinician [53]. It is notable that the laryngeal irritation signs may also be the result of non-reflux etiologies, such as allergy, smoking, or voice abuse [21]. Accurate laryngoscopic assessment of LPR is likely to be difficult, and it is not recommended to make a diagnosis of LPR solely based on laryngoscopic results $[21,37,42,53]$.

\section{Reflux Finding Score (Table 3)}

The RFS is an eight-item measure used by clinicians to rate the severity of signs of inflammation revealed in laryngoscopic examinations, including subglottic edema (pseudosulcus), ventricular obliteration, erythema or hyperemia, vocal fold edema, diffuse laryngeal edema, posterior commissure hypertrophy, granuloma or granulation tissue (Figure 1 and Video 1), and thick endolaryngeal mucus. The clinicians rates the severity of each symptom by assigning scores from 0 (normal) to 26 (worst possible score). LPR can be diagnosed with $95 \%$ certainty in cases where the RFS exceeds 7 [54]. It can also be used to track treatment responses in patients. The RFS and RSI both help to improve the accuracy of LPR diagnoses and evaluate the efficacy of treatments. The RFS is a cost-efficient method, which can be included in otolaryngologic examinations to facilitate the diagnosis of LPR $[49,50,54]$.

\section{Dual-Sensor $\mathrm{pH}$ Probe}

The 24-hour dual-sensor $\mathrm{pH}$ probe (simultaneous esophageal and pharyngeal) is considered the gold standard in the diagnosis of GERD, with sensitivity of $93.3 \%$ and specificity of $90.4 \%$, when using a cut-off value of $4.5 \%$ of total time with $\mathrm{pH}<4$ during a 24-hour period [55]. Ambulato$\mathrm{ry} \mathrm{pH}$ probe-monitoring is often applied to evaluate the efficacy of drug treatment in cases of LPR [12]; however, it is considered a less reliable test for confirming LPR $[11,14]$. This is primarily due to the difficulties involved in interpreting $\mathrm{pH}$ monitoring data and a lack of consensus on normal pH limits, number of events, and probe placement $[11,56,57]$. Another concern with $\mathrm{pH}$ probe-monitoring is its inability to detect gaseous and/or nonacid refluxate, which are potentially harmful to the laryngopharynx. As a result, intraluminal impedance testing is generally regarded as a superior approach [14].

\section{Upper Gastrointestinal Endoscopy}

UGE is also referred to as esophagogastroduodenoscopy (EGD). UGE can detect signs associated with GERD, such as mucosal injury, esophagitis, and Barrett esophagus as well as other complications and malignancies; however, UGE has proven less useful in detecting LPR than in identifying GERD $[12,18]$. In one study, UGE revealed esophageal lesions in $50 \%$ of GERD patients and in less than $20 \%$ of LPR laryngitis patients [58]. For patients presenting warning signs of complications (i.e., chronic cough, hoarseness, or dysphagia) or malignancies, it is recommended that they be referred to specialists, such as otolaryngologists, gastroenterologists, and pulmonologists [11].

\section{Other Tests}

Other tests have been also used to facilitate the diagnosis of LPR. Barium swallow esophagrams allow clinicians to screen the esophagus for related pathologies [12]. Alternative diagnostic techniques have also been devised to explore the associations between the LPR and histomolecular findings, including salivary epidermal growth factor, immunologic markers, laryngeal mucosa gene expression, and histologic changes [59-61].

\section{Behavior Modifications}

It is important that LPR is diagnosed and treated effectively. A failure to do so can lead to chronic cough, granulation of arytenoids, and/or ulcers on the vocal folds. This condition has also been linked to asthma, bronchitis, chronic rhinitis, sinusitis, and otitis media. Researchers have reported potential associations between acid reflux and esophageal, oropharyngeal, and hypopharyngeal neoplasms [62].

Studies have found that approximately half of the patients with mild LPR can avoid symptoms by implementing changes in their lifestyle [27]. 


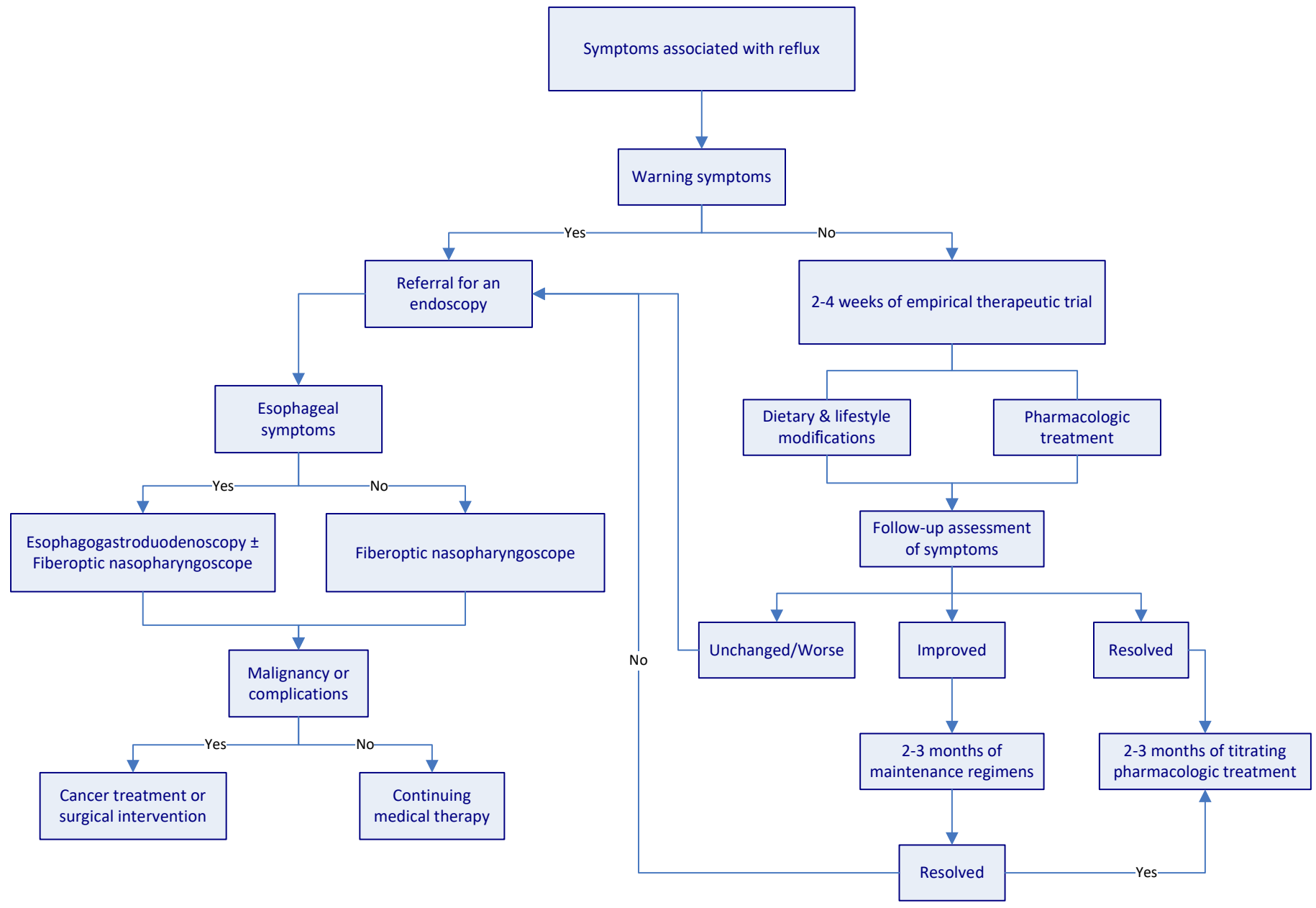

Figure 2. Algorithm for assessment and management of reflux disease.

These lifestyle changes are related to eating, drinking, and other habits. For example, raising the bed at the head side has been shown to prevent LPR symptoms. It is also recommended that patients quit smoking, lose weight, and wear loose clothing.

\section{Dietary Modifications}

LPR symptoms may be reduced by changing dietary habits. Patients are advised to eat food early (at least two hours before bedtime) to allow time for digestion before lying down [11]. Moreover, patients with acid reflux diseases are also advised against ingesting too much coffee [26] or carbonated drinks, which are known to affect acidity and cause reflux [63].

Spicy foods irritate the lower esophageal mucosa leading to heartburn and a burning sensation in their chests. High-fat foods and chocolate are known to prolong gastric emptying, and high-fat foods take longer to digest and have been associated with higher incidences of GERD and erosive esophagitis [64]. Note that some studies have reported that a high-fat diet has no effect on esophageal acid exposure or transient relaxation of lower esophageal sphincter [65-67]. Nonetheless, patients should be advised to avoid fatty diets to facilitate digestion and promote overall health. A high-calorie diet can also affect esophageal acid exposure. One study found that a high-calorie diet was associated with prolonged acidity in the stomach, which could aggravate reflux symptoms [68].

\section{Lifestyle Changes}

Reflux diseases are known as lifestyle diseases. Patients are therefore advised to avoid smoking, as it is known to cause acid production [11]. Smoking cigarettes is directly correlated with acid retention leading further to slow clearance of esophageal acid. Smokers have also been shown to have a higher incidence of reflux symptoms, compared to non-smokers $[69,70]$.

Researchers have identified a direct link between the consumption of alcoholic drinks and acid exposure and reflux. Alcoholic drinks of all types are a direct cause of heartburn. Consuming large quantities of alcohol poses the same risks, regardless of whether it was beer, wine, or spirits. Wine and beer have also been found to cause reflux, even in small quantities. Endoscopic studies have revealed that white wine and beer have similar effects on reflux esophagitis and abnormal pH levels. White wine has a more pronounced effect on acid exposure than does red wine [71-74].

\section{Weight Reduction}

Weight reduction is essential for patients suffering from LPR and GERD, due to the prevalence of these symptoms in obese patients. Researchers have shown a strong relationship between obesity and acid reflux [75], and a high body mass index (BMI) is directly related to acid reflux $[76,77]$. Weight gain can aggravate reflux symptoms and weight loss can have the reverse effect, allowing patients to reduce taking reflux medications $[78,79]$.

\section{Exercise}

Patients are advised to participate in exercise sessions of at least 30 minutes each day as a guard against reflux symptoms. Patients who are less active physically are more at risk of developing reflux problems [80,81].

\section{Medication}

Acid suppression via proton pump inhibitors (PPIs) is the mainstay of medical treatment for LPR. H2-receptor antagonists (H2AT), prokinetic agents, and mucosal cytoprotectants (e.g., sucralfate) may provide ad- 
ditional benefits [11,14,82]. Neuromodulators (e.g., tricyclic antidepressants, gabapentin, and pregabalin) may be an option for patients with symptoms that are not relieved by acid suppression, particularly in cases where laryngeal sensitivity (neuropathy) appears to be contributing to symptoms of LPR $[11,33,35,83]$. LPR treatment generally requires an aggressive approach, including high doses of PPIs over long periods (twice daily for $3-4$ months) $[10,12,14]$. Note that the efficacy of PPIs in LPR treatment is controversial and has not been conclusively proven [84-88].

\section{Surgery}

Surgery is usually a last resort in LPR treatment [11,89-91]. Patients should be warned that the response of their laryngeal symptoms to surgery is uncertain. Surgery should only be used in cases where patients responded to PPI therapy but did not achieve complete relief of LPR symptoms.

\section{Recommended Approaches to Reflux Assessment}

There are, as yet, no multidisciplinary approaches to the assessment and management of LPR [13]. It is still difficult to differentiate among reflux disorders, such as LPR and GERD, due to an overlap of symptoms. There is also some controversy about the routine use of endoscopy for patients with reflux disorder on their initial visit. Based on previous research, we developed the algorithm shown in Figure 2, with the aim of streamlining the assessment and management of reflux disorders, including LPR and GERD.

Patients with symptoms suggestive of complications or malignancies (e.g., dysphagia) require a referral to specialists for an endoscopic examination. Chest pain is seldom a symptom indicative of LPR; therefore, it is important to differentiate between cardiac from non-cardiac chest pains before considering LPR as a potential culprit. Chest X-rays may be required to exclude the possibility of lung disorders for patients presenting with chronic cough ( 2 or more weeks). Hoarseness is sometimes associated with uncomplicated LPR; however, lingering hoarseness for more than 2 weeks warrants an investigation of potential complications, including underlying vocal cord paralysis or lesions. This would involve referral to an otolaryngologist for laryngoscopic examination.

In primary care units, the diagnosis may be based primarily on LPR-associated symptoms and a therapeutic trial that includes lifestyle changes, dietary modifications, and the short-term use of PPIs. If LPR-related symptoms can be resolved within 2-4 weeks of a therapeutic trial using PPIs or H2AT, titrating therapy at the lowest dosage may be required for 2-3 months. Patients who show a less than complete improvement in symptoms may require a maintenance regimen for 2-3 months before initiating titrating pharmacologic treatment. It is suggested that patients are referred to specialists in the event that short-term therapeutic trials fail.

\section{Summary and Conclusion}

LPR is clinically distinct from GERD. LPR is very common, particularly among the elderly. Numerous existing methods provide useful diagnostic information on LPR, including endoscopic evidence of mucosal damage, demonstration of reflux events by multichannel impedance and $\mathrm{pH}$-monitoring studies, radiography, esophageal manometry, spectrophotometric measurement of bile reflux, and mucosal biopsy. Nonetheless, there remains some controversy regarding the appropriate course of action in the diagnosis of LPR, and no test is considered conclusively reliable.

LPR symptoms can be alleviated or eliminated by adopting changes in lifestyle, such as dietary, behavioral, and lifestyle habits. Patients are also advised to avoid sweet and fried foods, refrain from smoking and drinking, and wear loose comfortable clothing. They should also try to reduce stress in their lives and reduce their weight. Further investigations into alternative causes of laryngeal symptoms, including allergy, sinusitis, or pulmonary disorders, should be considered for patients who fail to respond to LPR treatments.

The risk of misdiagnosis based on reliable medical history records is relatively small. When the diagnosis is in question or the therapeutic response to PPIs is unsatisfactory, referral to a specialist is required to confirm the diagnosis of LPR.

\section{Article Information}

*Correspondence: Chin-Lung Kuo, MD, PhD

Department of Otolaryngology-Head and Neck Surgery, Taoyuan Armed

Forces General Hospital, No.168, Zhongxing Rd., Longtan Township,

Taoyuan County 32551, Taiwan. Email: drkuochinlung@gmail.com

Received: Mar. 01, 2018; Accepted: May 30, 2018; Published:Jan. 09, 2019

DOI: 10.24983/scitemed.aohns.2019.00094

Copyright @ 2019 The Author. This is an open-access article distributed under the terms of the Creative Commons Attribution 4.0 International License (CC-BY).

Funding: This study was sponsored by grants from the Medical Affairs Bureau, Ministry of National Defense (MAB-107-099), and Taoyuan Armed Forces General Hospital (AFTYGH No. 10734).

\section{Conflict of Interest: None}

\section{Keywords}

Esophageal; laryngopharyneal; laryngoscopy; proton pump inhibitor; reflux; update.

\section{References}

1. Postma GN, Halum SL. Laryngeal and pharyngeal complications of gastroesophageal reflux disease. GI Motility online 2006.

2. Campagnolo AM, Priston J, Thoen RH, Medeiros T, Assunção AR. Laryngopharyngeal reflux: diagnosis, treatment, and latest research. Int Arch Otorhinolaryngol 2014;18(2):184-191.

3. Koufman JA. Laryngopharyngeal reflux is different from classic gastroesophageal reflux disease. Ear Nose Throat J 2002;81(9 Suppl 2):7-9.

4. Kahrilas PJ, Shaheen NJ, Vaezi MF, American Gastroenterological Association Institute, Clinical Practice and Quality Management Committee. American Gastroenterological Association Institute technical review on the management of gastroesophageal reflux disease. Gastroenterology 2008;135(4):1392-1413, 1413 e1-e5.

5. Zerbib F, Stoll D. Management of laryngopharyngeal reflux: an unmet medical need. Neurogastroenterol Motil 2010;22(2):109-112.

6. Pearson JP, Parikh S, Orlando RC, et al. Review article: reflux and its consequences--the laryngeal, pulmonary and oesophageal manifestations. Conference held in conjunction with the 9th International Symposium on Human Pepsin (ISHP) Kingston-upon-Hull, UK, 21-23 April 2010. Aliment Pharmacol Ther 2011;33 Suppl 1:1-71.

7. Al-Saab F, Manoukian JJ, Al-Sabah B, et al. Linking laryngopharyngeal reflux to otitis media with effusion: pepsinogen study of adenoid tissue and middle ear fluid. J Otolaryngol Head Neck Surg 2008;37(4):565-571.

8. Alharethy S, Baqays A, Mesallam TA, et al. Correlation between allergic rhinitis and laryngopharyngeal reflux. Biomed Red Int 2018; 2018:2951928.

9. Weldon D: Laryngopharyngeal reflux and chronic sinusitis. Curr Allergy Asthma Rep 2007;7(3):197-201.

10. Diamond L: Laryngopharyngeal reflux--it's not GERD. JAAPA 2005; 18(8):50-53.

11. Franco RA Jr. Laryngopharyngeal reflux. In: UpToDate, Kunins L (Ed), UpToDate, Waltham, MA. Available at: https://www.uptodate.com/ contents/laryngopharyngeal-reflux. Accessed March 30, 2018.

12. Koufman JA, Aviv JE, Casiano RR, Shaw GY. Laryngopharyngeal reflux: position statement of the committee on speech, voice, and swallowing disorders of the American Academy of Otolaryngology-Head and Neck Surgery. Otolaryngol Head Neck Surg 2002;127(1):32-35.

13. Gelardi M, Ciprandi G. Focus on gastroesophageal reflux (GER) and laryngopharyngeal reflux (LPR): new pragmatic insights in clinical 
practice. J Biol Regul Homeost Agents 2018;32(1 Suppl. 2):41-47.

14. Ford CN. Evaluation and management of laryngopharyngeal reflux. JAMA 2005;294(12):1534-1540.

15. Salihefendic N, Zildzic M, Cabric E. Laryngopharyngeal Reflux Disease - LPRD. Med Arch 2017;71(3):215-218.

16. Hershcovici T, Fass R. Nonerosive Reflux Disease (NERD) - An Update. J Neurogastroenterol Motil 2010;16(1):8-21.

17. Sivarao DV, Goyal RK. Functional anatomy and physiology of the upper esophageal sphincter. Am J Med 2000;108 Suppl 4a:27S-37S.

18. Koufman JA. The otolaryngologic manifestations of gastroesophageal reflux disease (GERD): a clinical investigation of 225 patients using ambulatory 24-hour $\mathrm{pH}$ monitoring and an experimental investigation of the role of acid and pepsin in the development of laryngeal injury. Laryngoscope 1991;101(4 Pt 2 Suppl 53):1-78.

19. Belafsky PC, Postma GN, Koufman JA. Laryngopharyngeal reflux symptoms improve before changes in physical findings. Laryngoscope 2001;111(6):979-981

20. Vakil N, van Zanten SV, Kahrilas P, Dent J, Jones R, Global Consensus Group. The Montreal definition and classification of gastroesophageal reflux disease: a global evidence-based consensus. Am J Gastroenterol 2006;101(8):1900-1920; quiz 1943.

21. Katz PO, Gerson LB, Vela MF. Guidelines for the diagnosis and management of gastroesophageal reflux disease. Am J Gastroenterol 2013;108(3):308-328; quiz 329.

22. Groome M, Cotton JP, Borland M, McLeod S, Johnston DA, Dillon JF Prevalence of laryngopharyngeal reflux in a population with gastroesophageal reflux. Laryngoscope 2007;117(8):1424-1428.

23. Johnston N, Knight J, Dettmar PW, Lively MO, Koufman J. Pepsin and carbonic anhydrase isoenzyme III as diagnostic markers for laryngopharyngeal reflux disease. Laryngoscope 2004;114(12):2129-2134.

24. Johnston N, Yan JC, Hoekzema CR, et al. Pepsin promotes proliferation of laryngeal and pharyngeal epithelial cells. Laryngoscope 2012;122(6):1317-1325.

25. Sasaki CT, Marotta J, Hundal J, Chow J, Eisen RN. Bile-induced laryngitis: is there a basis in evidence? Ann Otol Rhinol Laryngol 2005;114(3):192-197

26. Lillemoe KD, Johnson LF, Harmon JW. Role of the components of the gastroduodenal contents in experimental acid esophagitis. Surgery 1982;92(2):276-284.

27. Hanson DG, Jiang J. Diagnosis and management of chronic laryngitis associated with reflux. Am J Med 2000;108 Suppl 4a:112S-119S.

28. Aviv JE, Liu H, Parides M, Kaplan ST, Close LG. Laryngopharyngeal sensory deficits in patients with laryngopharyngeal reflux and dysphagia. Ann Otol Rhinol Laryngol 2000;109(11):1000-1006.

29. Altman KW, Haines GK 3rd, Hammer ND, Radosevich JA. The $\mathrm{H}+$ / $\mathrm{K}+-$ ATPase (proton) pump is expressed in human laryngeal submucosal glands. Laryngoscope 2003;113(11):1927-1930.

30. Roussa $E$, Thévenod $F$. Distribution of V-ATPase in rat salivary glands. Eur J Morphol 1998;36 Suppl:147-152.

31. Basseri B, Conklin JL, Mertens RB, Lo SK, Bellack GS, Shaye OA. Heterotopic gastric mucosa (inlet patch) in a patient with laryngopharyngeal reflux (LPR) and laryngeal carcinoma: a case report and review of literature. Dis Esophagus 2009;22(4):E1-5.

32. Chong $\mathrm{VH}$, Jalihal A. Heterotopic gastric mucosal patch of the esophagus is associated with higher prevalence of laryngopharyngeal reflux symptoms. Eur Arch Otorhinolaryngol 2010;267(11):1793-1799.

33. Cobeta I, Pacheco A, Mora E. The role of the larynx in chronic cough. Acta Otorrinolaringol Esp 2013;64(5):363-368.

34. Bucca CB, Bugiani M, Culla B, et al. Chronic cough and irritable larynx. J Allergy Clin Immunol 2011;127(2):412-419.

35. Norris BK, Schweinfurth JM. Management of recurrent laryngeal sensory neuropathic symptoms. Ann Otol Rhinol Laryngol 2010;119(3):188-191

36. Hickson C, Simpson CB, Falcon R. Laryngeal pseudosulcus as a predictor of laryngopharyngeal reflux. Laryngoscope 2001;111(10): 1742-1745.

37. Book DT, Rhee JS, Toohill RJ, Smith TL. Perspectives in laryngopharyngeal reflux: an international survey. Laryngoscope 2002;112(8 Pt 1):1399-1406.

38. Lee BE, Kim GH. Globus pharyngeus: a review of its etiology, diagnosis and treatment. World J Gastroenterol 2012;18(20):2462-2471.

39. J Dent, J Brun, A Fendrick, et al. An evidence-based appraisal of reflux disease management--the Genval Workshop Report. Gut 1999, 44 Suppl 2:S1-16.

40. Reichel O, Issing WJ. Should patients with pH-documented laryngopharyngeal reflux routinely undergo oesophagogastroduodenoscopy? A retrospective analysis. J Laryngol Otol 2007;121(12):1165-1169.

41. Vaezi MF, Hicks DM, Abelson TI, Richter JE. Laryngeal signs and symptoms and gastroesophageal reflux disease (GERD): a critical assessment of cause and effect association. Clin Gastroenterol Hepatol 2003;1(5):333-344.

42. Qadeer MA, Swoger J, Milstein C, et al. Correlation between symptoms and laryngeal signs in laryngopharyngeal reflux. Laryngoscope 2005;115(11):1947-1952.

43. Dagli E, Yüksel A, Kaya M, Ugur KS, Turkay FC. Association of oral antireflux medication with laryngopharyngeal reflux and nasal resistance. JAMA Otolaryngol Head Neck Surg 2017;143(5):478-483.

44. Altundag A, Cayonu M, Salihoglu M, et al. Laryngopharyngeal reflux has negative effects on taste and smell functions. Otolaryngol Head Neck Surg 2016;155(1):117-121.

45. Emre Dinc M, Dalgic A, Avincsal MO, Ulusoy S, Celik A, Develioglu ON. An assessment of olfactory function in patients with laryngopharyngeal reflux disease. Acta Otolaryngol 2017;137(1):71-77.

46. Viliušytė E, Macaitytè R, Vaitkus A, Rastenytė D. Associations between peripheral vertigo and gastroesophageal reflux disease. Med Hypotheses 2015;85(3):333-335.

47. Miura MS, Mascaro M, Rosenfeld RM. Association between otitis media and gastroesophageal reflux: a systematic review. Otolaryngol Head Neck Surg 2012;146(3):345-352

48. Górecka-Tuteja A, Jastrzębska I, Składzień J, Fyderek K. Laryngopharyngeal reflux in children with chronic otitis media with effusion. $J$ Neurogastroenterol Motil 2016;22(3):452-458.

49. Nunes HS, Pinto JA, Zavanela AR, Cavallini AF, Freitas GS, Garcia FE. Comparison between the reflux finding score and the reflux symptom index in the practice of otorhinolaryngology. Int Arch Otorhinolaryngol 2016;20(3):218-221.

50. Belafsky PC, Postma GN, Koufman JA. Validity and reliability of the reflux symptom index (RSI). J Voice 2002;16(2):274-277.

51. Milstein CF, Charbel S, Hicks DM, Abelson TI, Richter JE, Vaezi MF. Prevalence of laryngeal irritation signs associated with reflux in asymptomatic volunteers: impact of endoscopic technique (rigid vs. flexible laryngoscope). Laryngoscope 2005;115(12):2256-2261.

52. Ylitalo R, Lindestad PA, Ramel S. Symptoms, laryngeal findings, and 24-hour $\mathrm{pH}$ monitoring in patients with suspected gastroesophago-pharyngeal reflux. Laryngoscope 2001;111(10):1735-1741.

53. Branski RC, Bhattacharyya N, Shapiro J. The reliability of the assessment of endoscopic laryngeal findings associated with laryngopharyngeal reflux disease. Laryngoscope 2002;112(6):1019-1024.

54. Belafsky PC, Postma GN, Koufman JA. The validity and reliability of the reflux finding score (RFS). Laryngoscope 2001;111(8):1313-1317.

55. Madan K, Ahuja V, Gupta SD, Bal C, Kapoor A, Sharma MP. Impact of 24-h esophageal $\mathrm{pH}$ monitoring on the diagnosis of gastroesophageal reflux disease: defining the gold standard. J Gastroenterol Hepatol 2005;20(1):30-37

56. Vaezi MF, Schroeder PL, Richter JE. Reproducibility of proximal probe $\mathrm{pH}$ parameters in 24-hour ambulatory esophageal $\mathrm{pH}$ monitoring. Am J Gastroenterol 1997;92(5):825-829.

57. Reichel O, Issing WJ. Impact of different $\mathrm{pH}$ thresholds for 24-hour 
dual probe $\mathrm{pH}$ monitoring in patients with suspected laryngopharyngeal reflux.J Laryngol Otol 2008;122(5):485-489.

58. Vaezi MF. Laryngitis and gastroesophageal reflux disease: increasing prevalence or poor diagnostic tests? Am J Gastroenterol 2004;99(5):786-788.

59. Birchall MA, Bailey M, Gutowska-Owsiak D. et al. Immunologic response of the laryngeal mucosa to extraesophageal reflux. Ann Otol Rhinol Laryngol 2008;117(12):891-895.

60. Jette ME, Seroogy CM, Thibeault SL. Laryngeal T regulatory cells in the setting of smoking and reflux. Laryngoscope 2017;127(4):882887.

61. Eckley CA, Rios Lda S, Rizzo LV. Salivary egf concentration in adults with reflux chronic laryngitis before and after treatment: preliminary results. Braz J Otorhinolaryngol 2007;73(2):156-160.

62. Kuo CL, Chen YT, Shiao AS, Lien CF, Wang SJ. Acid reflux and head and neck cancer risk: A nationwide registry over 13 years. Auris Nasus Larynx 2015;42(5):401-405.

63. Fass R, Quan SF, O'Connor GT, Ervin A, Iber C. Predictors of heartburn during sleep in a large prospective cohort study. Chest 2005;127(5):1658-1666.

64. El-Serag HB, Satia JA, Rabeneck L. Dietary intake and the risk of gastro-oesophageal reflux disease: a cross sectional study in volunteers. Gut 2005;54(1):11-17.

65. Mangano M, Colombo P, Bianchi PA, Penagini R. Fat and esophageal sensitivity to acid. Dig Dis Sci 2002;47(3):657-660.

66. Pehl C, Pfeiffer A, Waizenhoefer A, Wendl B, Schepp W. Effect of caloric density of a meal on lower oesophageal sphincter motility and gastro-oesophageal reflux in healthy subjects. Aliment Pharmacol Ther 2001;15(2):233-239.

67. Penagini R. Fat and gastro-oesophageal reflux disease. Eur J Gastroenterol Hepatol 2000;12(12):1343-1345.

68. Fox M, Barr C, Nolan S, Lomer M, Anggiansah A, Wong T. The effects of dietary fat and calorie density on esophageal acid exposure and reflux symptoms. Clin Gastroenterol Hepatol 2007;5(4):439-444.

69. Watanabe $Y$, Fujiwara Y, Shiba M, et al. Cigarette smoking and alcohol consumption associated with gastro-oesophageal reflux disease in Japanese men. Scand J Gastroenterol 2003;38(8):807-811.

70. Kahrilas PJ, Gupta RR. The effect of cigarette smoking on salivation and esophageal acid clearance. J Lab Clin Med 1989;114(4):431-438.

71. Pehl C, Wendl B, Pfeiffer A. White wine and beer induce gastro-oesophageal reflux in patients with reflux disease. Aliment Pharmacol Ther 2006;23(11):1581-1586.

72. Pehl C, Wendl B, Pfeiffer A, Schmidt T, Kaess H. Low-proof alcoholic beverages and gastroesophageal reflux. Dig Dis Sci 1993;38(1):93-96.

73. Vitale GC, Cheadle WG, Patel B, Sadek SA, Michel ME, Cuschieri A. The effect of alcohol on nocturnal gastroesophageal reflux. JAMA 1987;258(15):2077-2079.

74. Pehl C, Pfeiffer A, Wendl B, Kaess H. Different effects of white and red wine on lower esophageal sphincter pressure and gastroesophageal reflux. Scand J Gastroenterol 1998;33(2):118-122.

75. El-Serag HB, Sonnenberg A. Opposing time trends of peptic ulcer and reflux disease. Gut 1998;43(3):327-333.

76. Savarino $E$, Zentilin $P$, Marabotto $E$, et al. Overweight is a risk factor for both erosive and non-erosive reflux disease. Dig Liver Dis 2011;43(12):940-945.

77. Dore MP, Maragkoudakis E, Fraley K, et al. Diet, lifestyle and gender in gastro-esophageal reflux disease. Dig Dis Sci 2008;53(8):20272032.

78. Anderson JW, Jhaveri MA. Reductions in medications with substantial weight loss with behavioral intervention. Curr Clin Pharmacol 2010;5(4):232-238.

79. Ness-Jensen E, Lindam A, Lagergren J, Hveem K. Weight loss and reduction in gastroesophageal reflux. A prospective population-based cohort study: the HUNT study. Am J Gastroenterol 2013;108(3): 376-382.

80. Nilsson M, Johnsen R, Ye W, Hveem K, Lagergren J. Lifestyle related risk factors in the aetiology of gastro-oesophageal reflux. Gut 2004;53(12):1730-1735.

81. Nocon M, Labenz J, Willich SN. Lifestyle factors and symptoms of gastro-oesophageal reflux - a population-based study. Aliment Pharmacol Ther 2006;23(1):169-174.

82. McGlashan JA, Johnstone LM, Sykes J, Strugala V, Dettmar PW. The value of a liquid alginate suspension (Gaviscon Advance) in the management of laryngopharyngeal reflux. Eur Arch Otorhinolaryngol 2009;266(2):243-251.

83. Halum SL, Sycamore DL, McRae BR. A new treatment option for laryngeal sensory neuropathy. Laryngoscope 2009;119(9):1844-1847.

84. Reimer C, Bytzer P. Management of laryngopharyngeal reflux with proton pump inhibitors. Ther Clin Risk Manag 2008;4(1):225-233.

85. Havas $\mathrm{T}$, Huang $\mathrm{S}$, Levy $\mathrm{M}$, et al. Posterior pharyngolaryngitis: double-blind randomised placebo-controlled trial of proton pump inhibitor therapy. Australian Journal of Oto-Laryngology 1999;3(3): 243-246.

86. Steward DL, Wilson KM, Kelly DH, et al. Proton pump inhibitor therapy for chronic laryngo-pharyngitis: a randomized placebo-control trial. Otolaryngol Head Neck Surg 2004;131(4):342-350.

87. Vaezi MF, Richter JE, Stasney CR, et al. Treatment of chronic posterior laryngitis with esomeprazole. Laryngoscope 2006;116(2):254-260.

88. Wo JM, Koopman J, Harrell SP, Parker K, Winstead W, Lentsch E. Double-blind, placebo-controlled trial with single-dose pantoprazole for laryngopharyngeal reflux. Am J Gastroenterol 2006;101(9):19721978; quiz 2169.

89. Swoger J, Ponsky J, Hicks DM. et al. Surgical fundoplication in laryngopharyngeal reflux unresponsive to aggressive acid suppression: a controlled study. Clin Gastroenterol Hepatol 2006;4(4):433-441.

90. Catania RA, Kavic SM, Roth JS, et al. Laparoscopic Nissen fundoplication effectively relieves symptoms in patients with laryngopharyngeal reflux. J Gastrointest Surg 2007;11(12):1579-1587; discussion 1587-1578.

91. Ogut F, Ersin S, Engin EZ, et al. The effect of laparoscopic Nissen fundoplication on laryngeal findings and voice quality. Surg Endosc 2007;21(4):549-554. 